\title{
SOCIOLOGY
}

\section{PUBLIC PLACES IN THE MODERN CITY: DAILY PRACTICES OF THEIR CREATION AND PRESENTATION BY THE INHABITANTS OF THE CITY}

\author{
PhD of Sociological Sciences Mikhno Nadiya \\ Ukraine, Dnipro, Oles Honchar Dnipro National University \\ Associate Professor at the Department of Sociology
}

DOI: https://doi.org/10.31435/rsglobal_ijitss/31012020/6876

\section{ARTICLE INFO}

Received 16 November 2019

Accepted 12 January 2020

Published 31 January 2020

\section{KEYWORDS}

city, urban space, public space, public sphere, public places.

\begin{abstract}
The main focus of this article is on defining the specific characteristics of public space organization in a modern Ukrainian city. The study identified the vector of change in the organization of public spaces in recent decades under the influence of changing socio-historical, ideological context and under the influence of globalization processes. It is determined that the main formats of using public spaces in the city today are pragmatic formats of use - the practice of commercialization of urban space, the practice of interaction with strangers, «domestication» of public space, «Europeanization» of public space, desacralization and marking of public space as safe and convenient.
\end{abstract}

Citation: Mikhno Nadiya. (2020) Public Places in the Modern City: Daily Practices of Their Creation and Presentation by the Inhabitants of the City. International Journal of Innovative Technologies in Social Science. 1(22). doi: 10.31435/rsglobal_ijitss/31012020/6876

Copyright: (C) 2020 Mikhno Nadiya. This is an open-access article distributed under the terms of the Creative Commons Attribution License (CC BY). The use, distribution or reproduction in other forums is permitted, provided the original author(s) or licensor are credited and that the original publication in this journal is cited, in accordance with accepted academic practice. No use, distribution or reproduction is permitted which does not comply with these terms.

Introduction. In recent years, social science is inherent in the theme of publicity in general and public space in particular. The focus in such cases falls open and accessible to any urban dweller space of the city. Openness and accessibility are considered to be sufficient conditions for implementation in a specific urban space free communication between the various segments of the population about the important issues of the urban community. In other words, the public space in the perspective of the contemporary scientific study of the city takes primarily the form of discursive interaction. The basis of the normal functioning of city life is the availability of different types of public spaces. Modern public spaces of the city are shared and adapted in places for a long stay of people where there is social interaction between them. The brightest examples of such places are city parks, squares, promenades, streets, shopping and cultural and recreational centers, cafes, etc. The quality of their accomplishment and content of social practices will depend on the success of public spaces. What public space can determine the attractiveness and quality of life of the city and also reflect the level of development of social life and culture.

In today's urban development, the functional imperative of urban public space is more differentiated and complicated. Cities that emerged from urbanization as one of the defining historical and cultural processes in the modern period can be described as «a new form of spatial and structural organization of life» [1].

Note that the publicity in the diversity of its manifestations is a well-developed topic in an interdisciplinary discourse in general and sociological in particular. The subject in its various aspects from public spaces in the political sphere to the socio-cultural definition of the boundaries of this phenomenon is presented in different years, the works of G. Zimmel, L. Wirth, R. Park, H. Arendt, 
J. Habermas, E. Goffman, R. Sennett, M. Davis. Recently on the background of the ongoing debate about the transformation of a public-private organization, contraction/expansion of the borders between these spheres of social life, interest in this issue is actively present in the works of A. Giddens, Z. Bauman, J. Baudrillard, S. Zukin, M. Castells, J. Urry, J. Alexander. The suggestions of Ukrainian sociologists to determine the nature of the phenomenon of publicity are theoretically relevant. First, it is interesting to define publicity as a reflection of the socio-cultural context, a form of social imaginary that is constituted around certain symbols, landmark events, places and things - components of the «common».Second, O. Khodus's approach to conceptualizing the phenomenon of privacy, and accordingly to publicity and public spaces in a social fabric. The horizon of which these two poles of social life exist in the constant dialectical unity of opposites, the mixing of constellations of spatial and discursive boundaries [2].

Research results. It must be emphasized that the concept of «public space» and «public sphere»the most important aspects of urban studies. Often, they are considered identical, but we'll stick to the scientific tradition extending from J. Habermas, where the public sphere is understood as broader and includes all social communication on political and social issues [3]. From this perspective, public space open and accessible meeting places - are an important element of the public sphere, according to the state of social relations in the urban environment. Open public space, according to many researchers, is an essential component of urban life. The public space of a city is understood, first of all, as open, generally accessible spaces, adapted for people to stay, for «communication of strangers», anonymous meetings of citizens - streets, squares, parks. According to American public space researcher L. Lofland, «City life was made possible by streamlining the urban population by their appearance and location in such a way that people in the city can learn a lot about people around them just by looking at each other» [4]. All this can happen in the first place - in public places of the city.

The public space has two dimensions - physical and social. The social aspect of public space is that it determines the interaction between the social agents, the public space is impossible without subjects interaction. Accordingly, social reality manifests itself in this kind of interaction is reflected in public space. In turn, social is objectified, inscribed in the space: «the physical space is a social construction and projection of social space, and is a social structure in the objectified state (e.g. city plan)». On the other hand, the public space of the city is implemented through the physical space. Under the physical elements of public space, we understand a set of geographically restricted material units (structures, plants, playgrounds, sidewalks, benches for sitting, etc.), which are placed in this space. Based on the artificial origin of public space, it is formed as a result of planned and spontaneous activities of social actors [5].

In modern conditions the city is the center of the economic and political sphere of human activity, a source of dynamism and creativity of culture, there is formed a special type of human interaction and the characteristic urban lifestyle. This is due to the ongoing process of urbanization, which covers the whole world. The objective process of continuous consolidation of large urban structures began in the twentieth century and becomes more intense every year. With the increase of the physical space of the urban environment new challenges of environmental, economic, political and social nature.

Thus, the city is a complex space that is constructed by humans and has a physical and a social dimension. Only through their interaction, the urban system continues its functioning. Human activity occurs in a specific space that has its own size and shape. The environment created as a result of architectural work can be defined as the physical space of the city (architectural ensembles, the network transport the city's parks, squares). Each element of the physical content of the city performs a specific function is the context of people's daily lives. Therefore, its quality determines the thoughts and feelings of the people, has a significant impact on the perception and identity in this world. Therefore, the dialogue between man and object-spatial sphere of the city is an integral part of his life [6].

In the modern city and changing the nature of urban communities. Researchers have noted the transition from a society based on work that is the basis of a socialist city, to community-based on living. Metamorphoses also occur in the change of the spatial structure of the city, namely, is ambiguous suburbanization and urban decentralization, commercialization of the center of the city the resettlement of inhabitants of the central parts for the allocation of premises for commercial purposes (trade and offices). J. Bodnar stresses the importance of considering the functions of areas in the social transformation of public space and development of urban communities, because of the square is the center of social life of the city, from their functions in the modern city depends on the intensity of social communication and social activity of residents and the like. 
In different historical periods in the cities of Ukraine becomes an actual execution of the public spaces of political, communication, recreational functions, territorial identity and identification. Now for the public spaces of the cities of Ukraine and, above all, of the Dnipro city is characterized by a significant transformation. They require the understanding and determination of the positive and negative effects of commercialization and privatization of public spaces, their separation, «closing», the unavailability of individual members of the community, virtualization, sanctification, the growing role of shopping malls, the «Europeanization».

Given these conditions let us dwell on the specifics of the organization of public places in the Dnipro city (specifically talking about the main square and the central waterfront), the emergence of new formats of public spaces. The features of their pragmatic use and functional load. In the urban landscape of the Dnipro are the different types of public spaces: open (parks, plazas); closed (shopping centers), mixed (boulevards with elements of open space and enclosed shopping centers, such as street restaurants, mobile coffee bars). The central part of the city most full of all these types of public spaces, the concentration of which sufficiently smoothly varies from the center to the periphery. Further from the center are such types of public spaces like promenades, and green areas - parks. It is also worth noting that the promenade to a greater extent performs the functions of public space is more significant in the estimation of saturation.

It is important to note that the transformation and use of the public spaces of the Dnipro correspond to European trends and, at the same time, have their own particular appearance and operation. This is due mainly to sociocultural conditions (national, historical, ideological), in which the formation of the spatial organization of the Ukrainian society, including in the urban dimension, which, moreover, still show a certain attraction to the Soviet past. However, it is obvious that the spatial variation of the cities of the Dnipro happens fairly quickly: if the transformation processes in European countries lasted a few decades, cities in the former Soviet Union the same path is overcome in two to three times faster.

It should be noted that the use of public spaces in the city activation when the city became the venue of important cultural and sports events (festivals, concerts, sports marathons). Preparation for these events includes a number of «cosmetic improvements»: asphalted streets, restored historic buildings, improve security, prohibits unauthorized street trade and the like. As a consequence, the public space of the Central part of the city for some time become the safe, clean, devoid of social problems. During the sports and cultural events creates temporary formats that use public spaces. An example of such a temporary format was the creation of the Central Square of the fan zone during the football championship or the construction of the temporary pedestrian bridge to the waterfront on the island, which held an international music festival.

It should be added that public spaces are not only places of leisure practices of residents. Interesting is one of the possible formats of pragmatic use, which can be called «local business» (the clearly visible practice of commercialization of urban space). In addition to officially registered shops, cafes, restaurants and other establishments that typically offers licensing services, there are also «natural» business. The latter we take the «street performers» (musicians, mimes, dancers) that regularly appear as on the waterfront and in the Central Square, there is his permanent place. This category includes a variety of traders «services» - for example, «coffeemobile», the flower vendors, souvenir products, the people who give out promotional products. That is life on Central square is closely connected with the culture of consumption. Principal consumption activities here - visit shops or restaurants, the contemplation of street performance, consumption of drinks or food directly into the open air (on a bench). In this regard, we agree with S. Zukin, who believes the consumption of basic public culture of the city. The researcher writes: «In public culture is the culture of the streets, a shopping Mall, where sociality follows the General pursuit of goods and risk outbreaks of differences» [7]. It is logical that in the background of the transition to consumer society, large cities of Ukraine were faced with the phenomenon of the transformation of urban space to the needs of the trade and service industries.

Important pragmatic format of the use of public spaces in the city is «interaction with strangers». As on the waterfront and in the Central Square of the atmosphere, which directs people to be relatively open to each other. We specify: in the category «interaction with strangers» we carried people-watching, active actions, as scrutiny of passers-by, please photograph any verbal contact, acts of demonstrative behavior. Regarding the latter, we note the following. Street is a stage on which everyone gets the chance to play your own play. It is noteworthy that this behavior becomes part of our everyday life practices. Here we took a particularly noisy and loud action, like weddings (which are often held on the waterfront) where 
there are guests, and the couple that quite actively behaves. To determine people who behave this way, White used the concept «street performers»: it is not the artists but the people who play everyday ideas [8]. For example, it can be men who are loudly discussing something of their own, or a married couple who is «alone» with everyone finds out a relationship, a campaign of friends that laugh out loud. It is clear that their feelings and emotional impulses can be real, but this does not negate the fact that such behavior is a performance aimed at the audience present. It is interesting that such demonstrative behavior is peculiar precisely to young people - people who need self-affirmation more than others, which our study confirmed.

The organization and use of public spaces- «domestication», which is clearly reflected in the design and architecture of the city. On the basis of obtained results, it can be argued that in Dnipro city the practice of «domestication» actively represented on the main square and on the waterfront. In particular, the semantics of «domestication» can be observed in the design of cafes and restaurants, which is on an open area, with a cozy blankets, pillows, lamps. Markers of «domestication» of public space by the inhabitants of the city may be different: seats on the steps or sidewalks, flower beds, eating in open public spaces (at the square, on the street, in the park), dancing and singing in the street that used to be the exclusive prerogative of the house or in the specially designated places. In the city this feature is especially common on the waterfront, where you can observe how the locals sitting on the steps near the famous «bowl of wishes». With the «domestication» connected «intimidate» public spaces that, according to R. Sennett, conveys the key characteristics of urban life in the twentieth century: urban residents «clogged» in their private scrolls, and the quantity and quality of open communication platforms that would allow them to leave their private «capsules» is constantly decreasing [9].

Researchers of public spaces of cities in post-socialist countries express the view of «Europeanization» as one of the types of their transformations. There is no common understanding of the concept of «Europeanization». Urban residents of western sociology are considered that public space - open public space with free access, with the potential for interaction and communication, free from control. The specific direction of the transformation of public spaces of the Dnipro is connected with their sanctification. In squares, parks, squares of the city, this process happens in two ways. First, as desecularization, that is the restoration of previously destroyed sacred objects (for example, the temple on the waterfront), and secondly, as the construction of new religious buildings (the temple on the embankment). And in the end, we would like to characterize this marker public space of the city as convenience and image. In this respect, the Central square and promenade give the impression of a safe place. First, all objects that are located here, be well to consider, secondly, they have good lighting, the third, located in the center of the city, that is in a place where is always crowded.

Conclusions. As a general conclusion, we note that the public spaces of modern Ukrainian cities are characterized by the presentation of a complex, ambiguous, and transformative social processes. These processes are manifested in various aspects of its functioning, the appearance of different formats. Of conventional-site public spaces become places of self-organization of local communities. They are recovering, restreeted, commercialized, filled with new meanings and forms of visual presentation.

\section{REFERENCES}

1. Tykheeva, Yu. (2007). Man in urban space (philosophical and anthropological foundations of urbanology). Retrieved from http://www.mosgu.ru/nauchnaya/publications/professor.ru/Tyheeva. [in Russian]

2. Khodus, O. (2018). The phenomenology of privacy: the experience of social and philosophical research. Dnipro: Lithograph. 394. [in Ukrainian]

3. Gritsanov, A. The public. Concepts and categories. Retrieved from http://ponjatija.ru/node/696 [in Russian]

4. Volokhovich, A. (2017). Moscow public and private spaces: synthesis, coexistence or competition. Retrieved from https://thewallmagazine.ru/public-and-private-spaces/. [in Russian]

5. Vagin, V. (2000). City sociology. Textbook for municipal managers M.:Moscow Public Scientific Fund. 169. [in Russian]

6. Rishko, A. (2013). Morphological structure of social space of Lviv city. Social Dimensions of Society. 5(16). 442-457. [in Ukrainian]

7. Musiyedov, O. (2016). Identity and the city: the experience of one study. Ukraina Moderna. Retrieved from http://uamoderna.com/blogy/oleksi-musiezdov/identychnist-ta-misto. [in Ukrainian]

8. Finkler, Y. (2013). National consciousness as the Habermas problem. The world of social communications. Retrieved from http://wsc.kymu.edu.ua/toms/10/047-049.pdf. [in Ukrainian]

9. Sobolevska, M. (2010). Between privacy and publicity: the paradoxes of modern society. Actual problems of sociology, psychology, pedagogy.10. 11-15. [in Ukrainian] 